University of Nebraska - Lincoln

DigitalCommons@University of Nebraska - Lincoln

2005

\title{
Auditory brainstem responses in the Eastern Screech Owl: An estimate of auditory thresholds
}

Elizabeth F. Brittan-Powell

Bernard Lohr

D. Caldwell Hahn

Robert J. Dooling

Follow this and additional works at: https://digitalcommons.unl.edu/usgsstaffpub

Part of the Geology Commons, Oceanography and Atmospheric Sciences and Meteorology Commons, Other Earth Sciences Commons, and the Other Environmental Sciences Commons

This Article is brought to you for free and open access by the US Geological Survey at DigitalCommons@University of Nebraska - Lincoln. It has been accepted for inclusion in USGS Staff -- Published Research by an authorized administrator of DigitalCommons@University of Nebraska - Lincoln. 


\title{
Auditory brainstem responses in the Eastern Screech Owl: An estimate of auditory thresholds
}

\author{
Elizabeth F. Brittan-Powell ${ }^{\mathrm{a})}$ and Bernard Lohr \\ Department of Psychology, University of Maryland, College Park, Maryland 20742 \\ D. Caldwell Hahn \\ USGS Patuxent Wildlife Research Center, Laurel, Maryland 20708-4019
}

Robert J. Dooling

Department of Psychology, University of Maryland, College Park, Maryland 20742

(Received 9 December 2004; revised 14 April 2005; accepted 18 April 2005)

\begin{abstract}
The auditory brainstem response (ABR), a measure of neural synchrony, was used to estimate auditory sensitivity in the eastern screech owl (Megascops asio). The typical screech owl ABR waveform showed two to three prominent peaks occurring within $5 \mathrm{~ms}$ of stimulus onset. As sound pressure levels increased, the ABR peak amplitude increased and latency decreased. With an increasing stimulus presentation rate, ABR peak amplitude decreased and latency increased. Generally, changes in the ABR waveform to stimulus intensity and repetition rate are consistent with the pattern found in several avian families. The ABR audiogram shows that screech owls hear best between 1.5 and $6.4 \mathrm{kHz}$ with the most acute sensitivity between $4-5.7 \mathrm{kHz}$. The shape of the average screech owl ABR audiogram is similar to the shape of the behaviorally measured audiogram of the barn owl, except at the highest frequencies. Our data also show differences in overall auditory sensitivity between the color morphs of screech owls. () 2005 Acoustical Society of America. [DOI: 10.1121/1.1928767]
\end{abstract}

PACS number(s): 43.64.Ri, 43.64.Tk [JAS]

Pages: $314-321$

\section{INTRODUCTION}

Owls (order Strigiformes) as a group have among the most sensitive hearing observed in birds. Most owls are crepuscular or nocturnal predators that must detect, localize, and capture prey under low light conditions. The hearing of owls appears to be adapted for these circumstances, and at least some species can capture prey in complete darkness using auditory cues alone (Konishi, 1973; Payne, 1971). Owls are known to be sensitive across a wide range of frequencies, with hearing being particularly acute at high frequencies compared with most other birds (Dooling et al., 2000; Dyson et al., 1998; Konishi, 1973; Van Dijk, 1973). High-frequency auditory limits in some owl species approach $14 \mathrm{kHz}$, noticeably higher than that for passerines and other nonpasserines, and is indicative of the importance of high frequencies to the nocturnal predatory behavior of these birds (Dyson et al., 1998). In contrast, songbirds, and other species that use vocal signals for communication have hearing abilities that reflect the predominance of such signals for the social behavior of these species. Most auditory work to date with owls has focused on medium-large birds, in particular the barn owl (Tyto alba): Tytonidae, a sound localization specialist. Unlike many owls in the family Strigidae, barn owls are not overtly territorial, have fairly limited vocal repertoires, and communicate acoustically over relatively short distances (Marti, 1992). As a comparison with larger

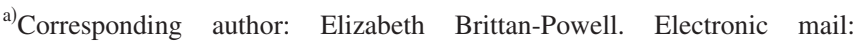
bbrittanpowell@psyc.umd.edu
}

owls, auditory tests were performed here with a small, common, very vocal species, the eastern screech owl (Megascops asio).

During the last several decades, the auditory brainstem response (ABR) has been used to study the functionality of the auditory system in a wide variety of vertebrates (e.g., Burkard et al., 1996a, 1996b; Donaldson and Rubel, 1990; Higgs et al., 2002a; Higgs et al., 2002b; Jewett, 1970; Jewett et al., 1970; Kenyon et al., 1998; Walsh et al., 1992), and the responses to auditory stimuli are similar across most vertebrate classes (e.g., Corwin et al., 1982; Walsh et al., 1992). Studies with birds have recently shown the value of the ABR as a method for assessing peripheral auditory system function and estimating hearing thresholds. In general, though, these studies comprise only a few species, particularly small nonpasserines such as the budgerigar and a few songbirds (e.g., Aleksandrov and Dmitrieva, 1992; Brittan-Powell and Dooling, 2004; Brittan-Powell et al., 2002; Dmitrieva and Gottlieb, 1992, 1994; Lucas et al., 2002; Saunders et al., 1973; Woolley et al., 2001; Woolley and Rubel, 1999; Wright et al., 2004). The present data on the screech owl represent an important addition to this database by providing the first complete ABR audiogram for a Strigiform bird (but see Köppl and Nickel, 2004; Moiseff et al., 1996). Two experiments involving $\mathrm{ABR}$ responses to click and tone-burst stimuli in the eastern screech owl were conducted. The effects of stimulus intensity and frequency on the ABR were examined in experiment 1 . The effects of stimulus presentation rate on wave latency and amplitude were examined in experiment 2 . 
The purpose of our tests with eastern screech owls was to determine (1) whether screech owl ABR characteristics were like those of other birds; (2) whether the ABR could be used as an estimate of auditory sensitivity in this species; and (3) whether estimated auditory sensitivity paralleled the vocal ability of the screech owl.

\section{METHODS}

Thirteen screech owls ( 8 males, 3 females, 2 female juveniles between five-six months of age) served as subjects in these experiments. All but four individuals ( 1 male, 1 female, and the 2 juveniles) were of the gray plumage morph of this species, which is the most common phenotype in the local area and throughout the northern portions of its geographic range (Gehlbach, 1994; Gehlbach, 1995). The birds were housed in an avian vivarium at the USGS Patuxent Wildlife Research Center and tested at the University of Maryland. All birds were sedated with an intramuscular injection of ketamine $(25-35 \mathrm{mg} / \mathrm{kg}$ ) and diazepam $(2 \mathrm{mg} / \mathrm{kg})$ prior to electrode placement. Subjects remained relatively motionless for up to $75 \mathrm{~min}$. After ABR data collection was completed, the bird was placed in a heated therapy unit and allowed to recover from sedation. The Animal Care and Use Committee at the University of Maryland and Patuxent Wildlife Research Center approved all animal use.

The procedure for recording ABRs has been described earlier (see Brittan-Powell and Dooling, 2004; BrittanPowell et al., 2002; Wright et al., 2004). Briefly, the bird was positioned so that the speaker (KEF SP 3235, Model 60S, frequency range $100 \mathrm{~Hz}$ to $20 \mathrm{kHz}$, KEF Electronics of America, Inc., Holliston, MA) was $20 \mathrm{~cm}$ from the bird's right ear $\left(45^{\circ}\right.$ azimuth relative to the bird's beak; $0^{\circ}$ elevation relative to the bird's right ear). Standard platinum alloy, subdermal needle electrodes, (Grass F-E2; West Warwick, RI) were twisted together to reduce electrical noise and placed just under the skin at the vertex of the skull (active), behind the ipsilateral pinna (reference), and behind the pinna of the ear contralateral to stimulation (left ear; ground). The stimulus presentation, ABR acquisition, equipment control, and data management were coordinated using a Tucker-Davis Technologies (TDT; Gainesville, FL, USA) System 3 modular rack-mount system controlled by a FI5 Gigabit interface module cable-linked 2.66-GHz Pentium4 PC containing a TDT PI5 Gigabit interface PCI card and running TDT "BIOSIG" software. Sound stimuli were generated using TDT "SIGGEN" software and fed through a RP2.1, which can synthesize and process wideband signals in real time. The RP2.1 fed to a TDT programmable attenuator (PA5), which directly drove the speaker. Recording electrodes were connected to the low-impedance Medusa Digital Biological Amplifier System (RA4L Headstage and RA16PA PreAmp; RA16BA Medusa Base station), which added an additional $10 \times$ gain. All biological signals were notch filtered at $60 \mathrm{~Hz}$ and bandpass filtered below $30 \mathrm{~Hz}$ and above $3000 \mathrm{~Hz}$ after collection using the BIOSIG program.

Tone bursts and clicks were both used as stimuli to generate the screech owl ABR. Stimulus intensities were calibrated in the free field by placing the $\frac{1}{2}$ in. microphone of a sound level meter (System 824; Larson Davis, Inc. Provo, UT) at the approximate position of the bird's right ear. Long duration tone bursts $(1000 \mathrm{~ms})$ were generated and played using the TDT SIGGEN program. Frequencies above $500 \mathrm{~Hz}$ were measured using the fast-weighting A scale on the sound level meter (dB SPL). The $\frac{1}{3}$ octave band filter on the sound level meter was used to measure the sound pressure level at $500 \mathrm{~Hz}$. The SPL required to match the amplitude of the click, as indicated on the sound level meter, was determined by adjusting the level of a $1000 \mathrm{~Hz}$ tone until the peak-topeak voltage was identical to that for the click (peak equivalent SPL; dB pSPL).

\section{EXPERIMENT 1: EFFECTS OF INTENSITY AND FREQUENCY ON THE ABR OF EASTERN SCREECH OWLS}

\section{A. Introduction}

Experiment 1 measured changes in the ABR waveform as a function of stimulus intensity and frequency. ABR thresholds (i.e., the lowest intensity at which detectable responses were observed) were computed as an estimate of hearing sensitivity in the screech owl, and this estimate was then compared to audiograms of other species.

\section{B. Stimuli}

Thirteen eastern screech owls were presented with multiple-intensity stimulus trains (see Brittan-Powell and Dooling, 2004; Brittan-Powell et al., 2002) that varied in frequency and intensity. Each train consisted of nine single clicks or single frequency tone bursts that increased in intensity. These trains were presented at a rate of $3 / \mathrm{s}$. The rectangular-pulse broadband clicks were $0.1 \mathrm{~ms}$ in duration with an interstimulus interval (ISI) of $25 \mathrm{~ms}$. Tone burst stimuli ranged from $0.5-12 \mathrm{kHz}$ and were $5 \mathrm{~ms}$ in duration (1 $\mathrm{ms} \mathrm{cos}^{2}$ rise/fall) with $20 \mathrm{~ms}$ ISI. Each ABR represents the response of 300 alternating phase stimulus presentations, sampled at $20 \mathrm{kHz}$ for $235 \mathrm{~ms}$ following onset of the stimulus. Each intensity level was replicated.

\section{Analysis}

ABR waveforms produced in response to high intensities were examined visually. We chose a range of $1-10 \mathrm{~ms}$ to measure a response. Since test stimulus intensities in the region of threshold differed by $5 \mathrm{~dB}$, ABR thresholds were defined as the intensity $2.5 \mathrm{~dB}$ (one-half step in intensity) below the lowest stimulus level at which a response could be visually detected on the trace, regardless of wave (see, for example, Brittan-Powell and Dooling, 2004; Brittan-Powell et al., 2002). Thresholds were estimated for each replication, and the average of the two estimates was used in statistical tests.

\section{Results}

As the intensity of stimulation increased, ABR amplitudes increased and peak latencies decreased. Figure 1 shows typical ABR waveforms for an adult screech owl to a click and 3 frequencies $(2.0,4.0$, and $6.4 \mathrm{kHz})$ as a function of 

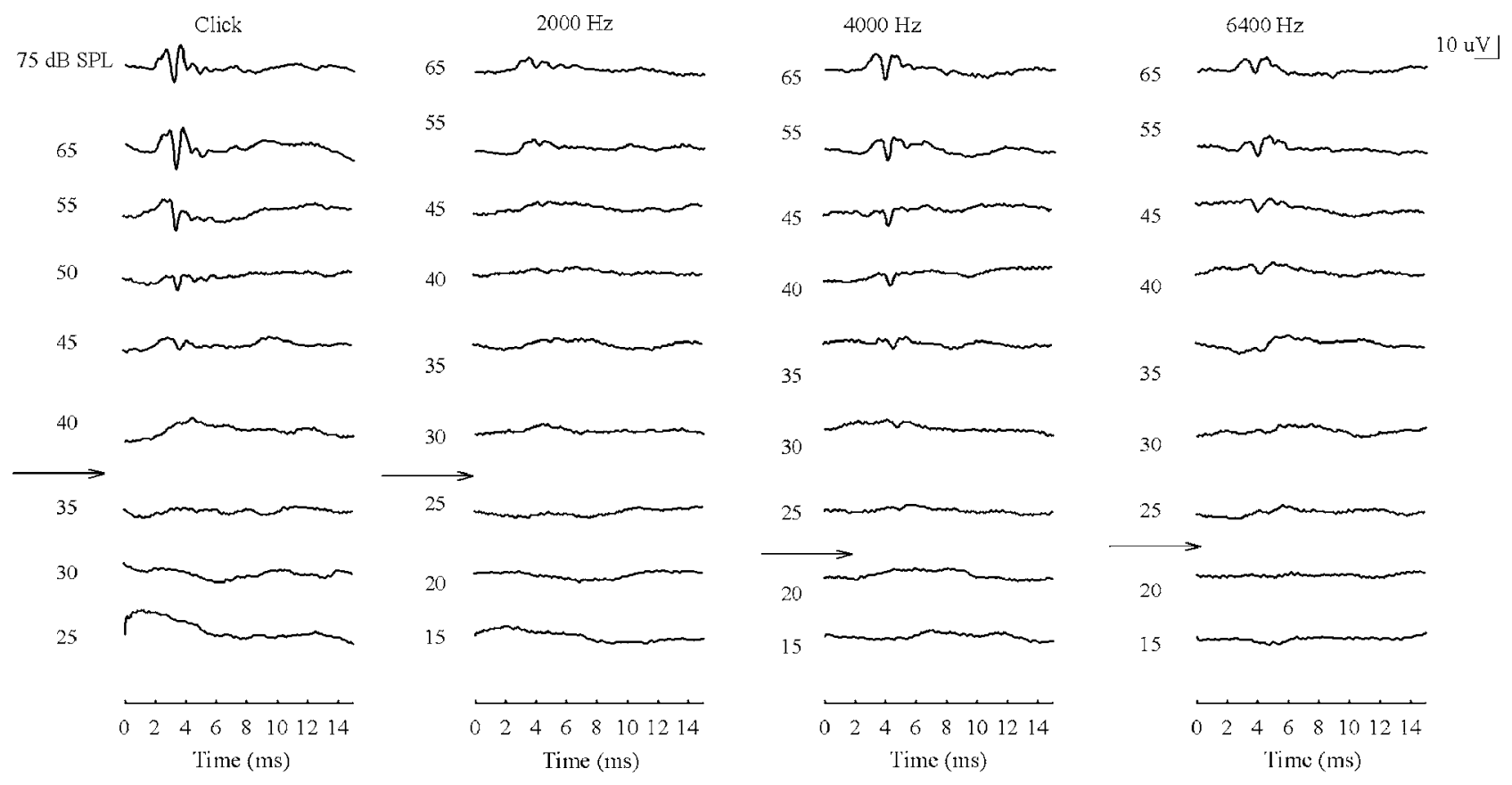

FIG. 1. ABR waveforms for a single owl for the click stimulus and 2000, 4000, and $6400 \mathrm{~Hz}$ tones as a function of SPL. Amplitude decreased and latency increased with decreasing SPL. Arrow along side of graph denotes the threshold estimates for this bird.

intensity. Visual examination of the waveforms showed 2-3 prominent peaks that occurred within the first $4-5 \mathrm{~ms}$ after sound reached the owl's external ear canal, with the trough of peak 1 showing the largest deflection, a pattern found in other birds (Brittan-Powell and Dooling, 2004; BrittanPowell et al., 2002; Lucas et al., 2002; Moiseff et al., 1996; Wright et al., 2004). The average click threshold for all 13 owls was $32.69 \pm 1.46 \mathrm{~dB}$ pSPL (mean $\pm \mathrm{SE}$ ), with the click threshold being significantly lower for the rufous morph $(27.50 \pm 2.04 \mathrm{~dB}$ pSPL) than for the gray morph $\left(35.00 \pm 1.32 \mathrm{~dB}\right.$ pSPL) $\left[t_{(11)}=3.13, p<0.05\right]$. Male and female owls showed no difference in their ABR thresholds across frequencies $\left(F_{1,107}=4.08, p=0.071\right)$, so these data were combined. Figure 2(a) shows the average ABR thresholds for all owls tested. Figure 2(b) shows the average ABR thresholds for the nine eastern screech owls of the gray plumage morph and the four owls of the rufous plumage morph. Interestingly, the ABR thresholds for the rufous morph were $10-15 \mathrm{~dB}$ more sensitive than those for birds of the gray morph. A two-way repeated measures ANOVA showed significant differences between both morphs $\left(F_{1,107}\right.$ $=42.52, p<0.001)$ and frequencies $\left(F_{1,107}=194.44, p\right.$ $<0.001$ ), as well as the interaction of morph $x$ frequency $\left(F_{10,107}=3.52, p<0.001\right)$.

\section{EXPERIMENT 2: EFFECTS OF CLICK REPETITION RATE ON THE ABR OF EASTERN SCREECH OWLS}

\section{A. Introduction}

We investigated the effect of click repetition rate on ABR latency and amplitude. ABR changes to click repetition rate are often used to assess change in neural transmission (e.g., neural fatigue and adaptation; see the review in Hall, 1992) or for assessing brainstem neuropathology. Typically,

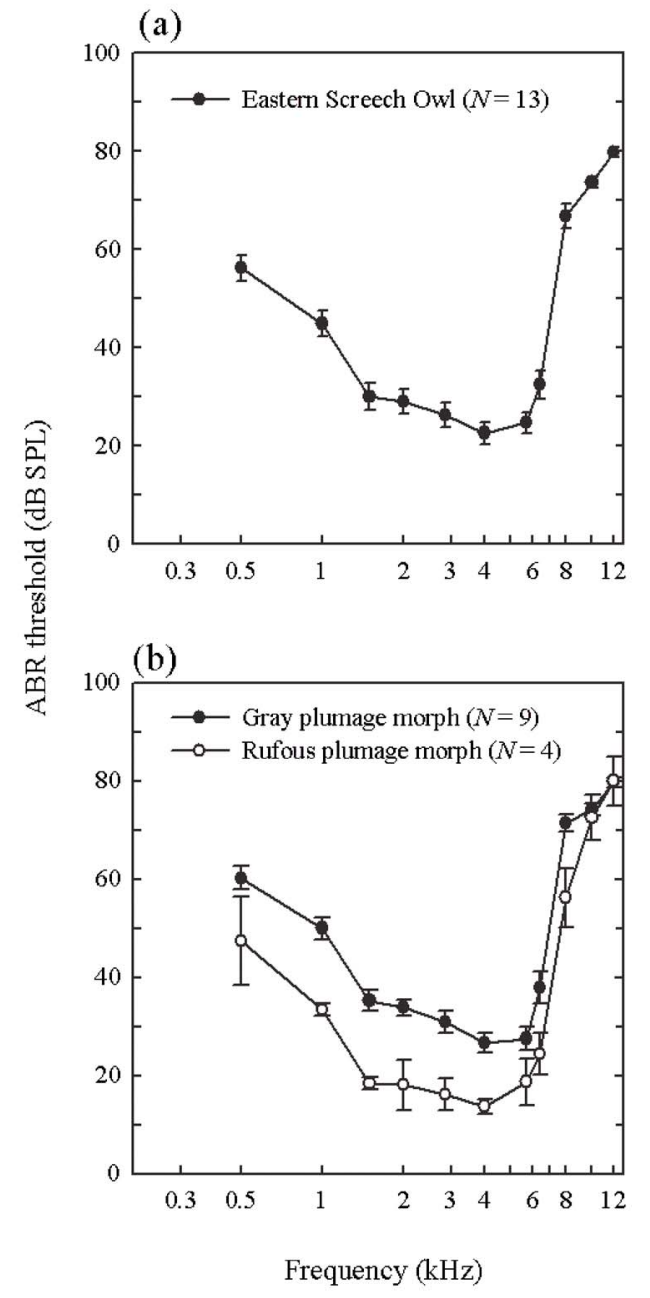

FIG. 2. (a) Average (+/- SE) ABR audiogram 13 eastern screech owls (Megascops asio). (b) Separate average ABR audiograms for birds of the gray plumage morph $(N=9)$ and the rufous plumage morph $(N=4)$.

Brittan-Powell et al:: Auditory brainstem responses in screech owls 
TABLE I. Average (+/-SE) latency and amplitude measures as a function of the repetition rate.

\begin{tabular}{lccccc}
\hline \hline & $5 \mathrm{~Hz}$ & $10 \mathrm{~Hz}$ & $30 \mathrm{~Hz}$ & $60 \mathrm{~Hz}$ & $90 \mathrm{~Hz}$ \\
\hline LATENCY (ms) & & & & & \\
Wave 1 & $1.40(0.06)$ & $1.43(0.05)$ & $1.45(0.05)$ & $1.46(0.06)$ & $1.49(0.05)$ \\
Wave 2 & $1.91(0.01)$ & $1.93(0.02)$ & $1.95(0.02)$ & $1.98(0.01)$ & $2.00(0.02)$ \\
Wave 3 & $2.54(0.04)$ & $2.55(0.06)$ & $2.62(0.08)$ & $2.65(0.08)$ & $2.69(0.08)$ \\
Wave 1-2 interval & $0.50(0.06)$ & $0.50(0.05)$ & $0.50(0.06)$ & $0.52(0.06)$ & $0.51(0.06)$ \\
Wave 1-3 interval & $1.13(0.10)$ & $1.12(0.11)$ & $1.17(0.13)$ & $1.19(0.13)$ & $1.20(0.13)$ \\
AMPLITUDE $(\mu \mathrm{V})$ & & & & $3.82(0.48)$ & $3.28(0.49)$ \\
Wave 1 & $6.33(0.56)$ & $5.91(0.55)$ & $4.48(0.43)$ & $2.64(0.43)$ & $2.21(0.31)$ \\
Wave 2 & $5.15(0.56)$ & $4.42(0.66)$ & $3.55(0.63)$ & $7.82(0.98)$ & $6.78(0.73)$ \\
Wave 3 & $8.83(1.83)$ & $9.91(1.98)$ & $9.54(1.70)$ & $1.61(0.30)$ & $1.58(0.26)$ \\
Ratio 1/2 & $1.29(0.17)$ & $1.53(0.30)$ & $1.47(0.28)$ & $0.52(0.08)$ & $0.51(0.08)$ \\
Ratio 1/3 & $0.92(0.23)$ & $0.73(0.16)$ & $0.55(0.11)$ & \\
\hline \hline
\end{tabular}

as click repetition rates increase, peak latencies of the ABR also increase and peak amplitudes of the ABR decrease, resulting in alterations of wave morphology (e.g., Burkard and Voigt, 1989; Donaldson and Rubel, 1990; Jewett and Romano, 1972). While such changes have been studied extensively in mammals, such as gerbils, cats, and rats, the only birds studied to date have been the white leghorn chick (Burkard et al., 1994) and the budgerigar (Brittan-Powell and Dooling, 2004; Brittan-Powell et al., 2002). The present results extend our knowledge of the effect of click repetition rate on ABR latency and amplitude by testing a Strigiform bird. Five of the birds (three males and two females) used in the previous experiment were tested in Experiment 2. All equipment and procedures have been previously described in detail (Brittan-Powell et al., 2002) and are the same as in Experiment 1, except where noted below.

\section{B. Stimuli}

Short duration, broadband clicks $(0.1 \mathrm{~ms})$ were presented at 5 rates: 5, 10, 30, 60, and 90 per second $(\mathrm{Hz})$. The click level was held constant at $100 \mathrm{~dB}$ pSPL. Each ABR represented the average response of 300 alternating stimulus presentations, sampled at $20 \mathrm{kHz}$ for $10 \mathrm{~ms}$ following onset of the stimulus. Each presentation rate was replicated.

\section{Analysis}

The first three wave components (designated wave 1, wave 2, and wave 3) were described by their amplitude and latency characteristics. Positive evoked potential peaks were identified by cursors, and associated amplitudes and latencies were automatically saved. Latencies to the waves were corrected for conduction delays between the sound source and the entrance of the ear canal of the animal $(0.58 \mathrm{~ms})$. The latency of the interwave interval was calculated as the difference in latency from wave 1 peak to wave 2 peak (1-2 interval) and wave 1 peak to wave 3 peak (1-3 interval). ABR wave amplitudes were measured as peak to baseline (wave 1) and peak to preceding trough (wave 2 and 3). The average latency and amplitude data for wave 1, 2, and 3 were calculated based on all replications (e.g., average latency for $5 \mathrm{~Hz}$ based on 2 replications for each of 5 birds). The statistical tests were conducted on the average latency and amplitude of each bird's two replicates.

\section{Results}

Like mammals and other birds, screech owl ABR responses are dependent on the temporal properties of the stimulus. Increasing click repetition rate resulted in increases in latency and decreases in amplitude for all waves (Table I). The general shape of the waveform also changed, especially at rates higher than $10 \mathrm{~Hz}$. Figure 3 shows ABR waveforms from a single bird in response to the click rates presented in this study. The latency of waves 1, 2, and 3 and the intervals 1-2 and 1-3 were evaluated with a two-way ANOVA; tables summarize the results. As the repetition rate increased, latency increased significantly for all three waves, but the interval between the waves remained fairly stable. Bonferroniadjusted posthoc comparisons showed that the lowest repetition rates $(5$ and $10 \mathrm{~Hz}$ ) resulted in significantly shorter latencies than higher repetition rates $(90 \mathrm{~Hz})$ across all three waves.

With an increased click repetition rate, the absolute amplitude decreased significantly for waves 1 and 2, as did the ratio of wave 1 to wave 3 (see summary Table II). Bonferroni-adjusted posthoc comparisons showed that amplitudes of waves 1 and 2 were significantly larger for lower repetition rates than for higher rates. The same trend was seen for wave 3 as well, but it was not significant. The mean wave 1 to wave 2 amplitude ratio was larger than 1.0 (i.e., the amplitude of wave 1 was larger than the amplitude of wave 2). However, the ratio of the two waves remained relatively constant across repetition rates suggesting that they were equally affected by increased presentation rate. The ratio of wave 1 to wave 3 , however, decreased as a function of increased click repetition rate, suggesting that the generators of the two waves were differentially affected by increased presentation rate.

\section{DISCUSSION}

The goals of this study were to determine (1) whether the ABR characteristics (e.g., thresholds and effects of stimulus presentation rate on neural synchrony) in a small Strigi- 


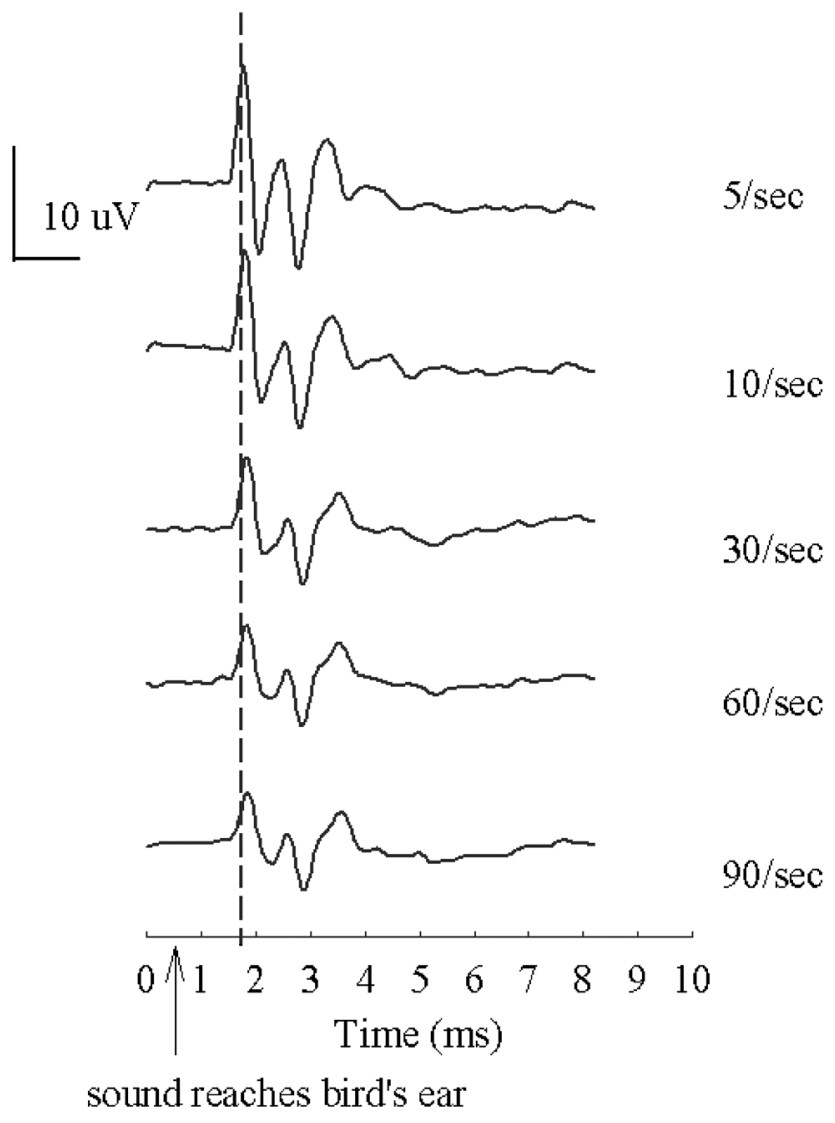

FIG. 3. Typical ABR waveform for an adult screech owl for each repetition rate. Increased rate caused increased latencies and decreased amplitudes, with the largest changes occurring at rates above $10 \mathrm{~Hz}$. An arrow denotes the time at which the stimulus reached the outer ear.

form bird, the eastern screech owl, were comparable to those of other birds, (2) whether the ABR could be used to obtain an estimate of auditory sensitivity in this species, and (3) whether the ABR estimates of auditory sensitivity paralleled the owls' vocal abilities.

\section{A. ABR morphology in screech owls}

Eastern screech owl ABR waveforms showed 2-3 measurable peaks that occurred within the first $5 \mathrm{~ms}$ after stimulation. These results are typical of findings with several other

TABLE II. Results of ANOVA for latency and amplitude as a function of the repetition rate.

\begin{tabular}{lccc}
\hline \hline $\begin{array}{l}\text { Dependent } \\
\text { variable }\end{array}$ & $N$ & F ratio & Probability \\
\hline Wave 1 latency & 5 & 7.54 & $p<0.001$ \\
Wave 2 latency & 5 & 16.98 & $<0.001$ \\
Wave 3 latency & 5 & 10.90 & $<0.001$ \\
Wave 1-2 interval & 5 & 0.72 & 0.59 \\
Wave 1-3 interval & 5 & 2.71 & 0.068 \\
Wave 1 amplitude & 5 & 51.00 & $<0.001$ \\
Wave 2 amplitude & 5 & 18.20 & $<0.001$ \\
Wave 3 amplitude & 5 & 2.86 & 0.058 \\
Ratio 1/2 & 5 & 1.58 & 0.229 \\
Ratio 1/3 & 5 & 5.25 & $<0.05$ \\
\hline \hline
\end{tabular}

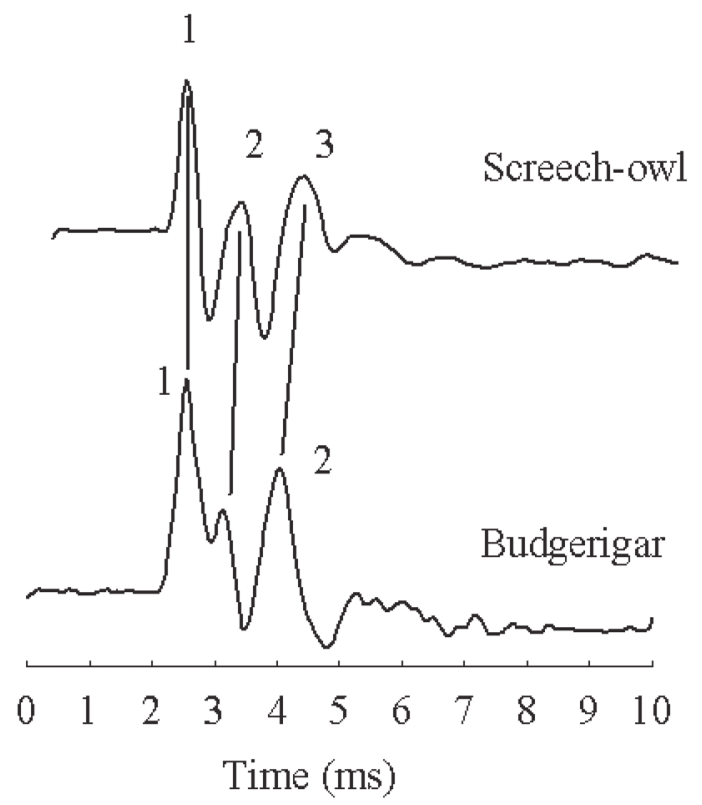

FIG. 4. A comparison of screech owl and budgerigar ABR waveforms in response to a $100 \mathrm{~dB}$ pSPL click stimulus. Budgerigar data is from BrittanPowell et al. (2002).

bird species (Brittan-Powell and Dooling, 2004; BrittanPowell et al., 2002; Lucas et al., 2002; Moiseff et al., 1996; Umemoto et al., 1993; Woolley et al., 2001; Woolley and Rubel, 1999; Wright et al., 2004). Figure 4 shows a comparison of ABR waveform responses to a $100 \mathrm{~dB}$ pSPL click in a screech owl (current study) and a budgerigar (from BrittanPowell et al., 2002). Wave 1 in most animals is consistently attributed to the auditory nerve. Given the similarity in time course and shape between the waveform of budgerigars and screech owls, it is likely that the auditory nerve is the neural generator for this first peak in the screech owl waveform as well.

While the ABR waveforms for budgerigars and screech owls are very similar in most respects (Fig. 4), the third peak in the owl waveform most likely corresponds to the second peak in the budgerigar waveform, given the timing and shape of the waveform (see the review in Brittan-Powell et al., 2002). Likewise, the second peak for the owl closely corresponds to the shoulder seen in wave 1 for the budgerigar. Based on similarities in latency in budgerigars, chickens (Katayama, 1985), and cats (Burkard et al., 1996a), BrittanPowell et al. (2002) argued that wave 2 in budgerigars may be generated by nucleus laminaris in the auditory brainstem of the budgerigar. To extend this reasoning to the screech owl, if wave 3 corresponds to the budgerigar wave 2, we suggest that wave 3 is most likely generated by nucleus laminaris.

With increasing click repetition rate, mammalian and avian ABRs all show increases in peak latencies and decreases in peak amplitudes (Brittan-Powell et al., 2002; Burkard et al., 1994; Burkard et al., 1996a, 1996b; Burkard and Voigt, 1989; Donaldson and Rubel, 1990; Lasky, 1997). The same effect was observed in screech owls (Table I). As the rate increased, there was a greater latency change for wave 3 than wave 2, which is similar to what has been found

Brittan-Powell et al:: Auditory brainstem responses in screech owls 
in other vertebrates. Furthermore, while waves 1 and 2 seem to be equally affected by increasing rate, wave 3 shows a slower rate of amplitude decrease as compared to wave 1 (see Table I). Together these results suggest screech owls show a pattern of ABR peaks similar to that of other vertebrates tested.

\section{B. ABR thresholds in screech owls}

Avian ABR thresholds yield estimates of hearing that are about $30 \mathrm{~dB}$ higher than direct behavioral measures of hearing [see Fig. 5(a) and the discussion in Brittan-Powell et al., 2002]. However, across vertebrates the ABR thresholds provide a good estimate of audiogram shape (e.g., Borg and Engström, 1983; Brittan-Powell et al., 2002; Stapells and Oates, 1997; Wenstrup, 1984; Wolski et al., 2003). The current study shows that screech owls have the typical U-shaped audiogram found in most bird species and hear fairly well over the range of $1.5-6.4 \mathrm{kHz}$. Figure 5(b) compares ABR thresholds for the screech owl in the current study and from a single barn owl (using the same procedures) with a behavioral audiogram for the barn owl (Dyson et al., 1998; Fay, 1988; Konishi, 1973). In general, the owl ABR thresholds are remarkably similar to each other and similar in shape to the barn owl behavioral audiogram, with the exception that ABR thresholds are 35-40 dB higher than behavioral estimates of auditory sensitivity across most frequencies. These data also suggest that the screech owl may be less sensitive than the barn owl at some of the higher frequencies since there is a large difference between the ABR audiograms around $8 \mathrm{kHz}$.

In the screech owls we tested, there is a statistical difference in the ABR thresholds between the gray and rufous plumage morphs. The owls of the rufous morph are not only more sensitive but this sensitivity difference varies as a function of frequency [as is evident in Fig. 2(b)].

Color polymorphism occurs naturally in many groups of animals, but in birds it has evolved most often in raptors (Roulin and Wink, 2004). In most cases, plumage variation in raptors is thought to be genetically controlled, rather than the influence of environmental factors such as diet (Roulin and Wink, 2004), and the screech owls in this study were all fed the same diet. A recent study involving the molecular basis of plumage polymorphism in a songbird has shown that the presence of distinct color morphs can be the result of a single gene mutation (Theron et al., 2001). Plumage polymorphism in screech owls is also likely to be genetically based (Gehlbach, 1994). Intermediates between the gray and rufous morphs (such as a "brown" phenotype) are common, suggesting the presence of more than two alleles or genes controlling plumage color in this species.

This result is intriguing, and we know of no other parallels. In some domesticated mammals, particularly certain breeds of dog, congenital sensorineural deafness is associated with certain phenotypic patterns of eye and coat color (Strain et al., 1992). In these cases, the auditory deficits linked to color patterns are also known to have a genetic basis, though the precise associations and mechanisms remain elusive (Juraschko et al., 2003).
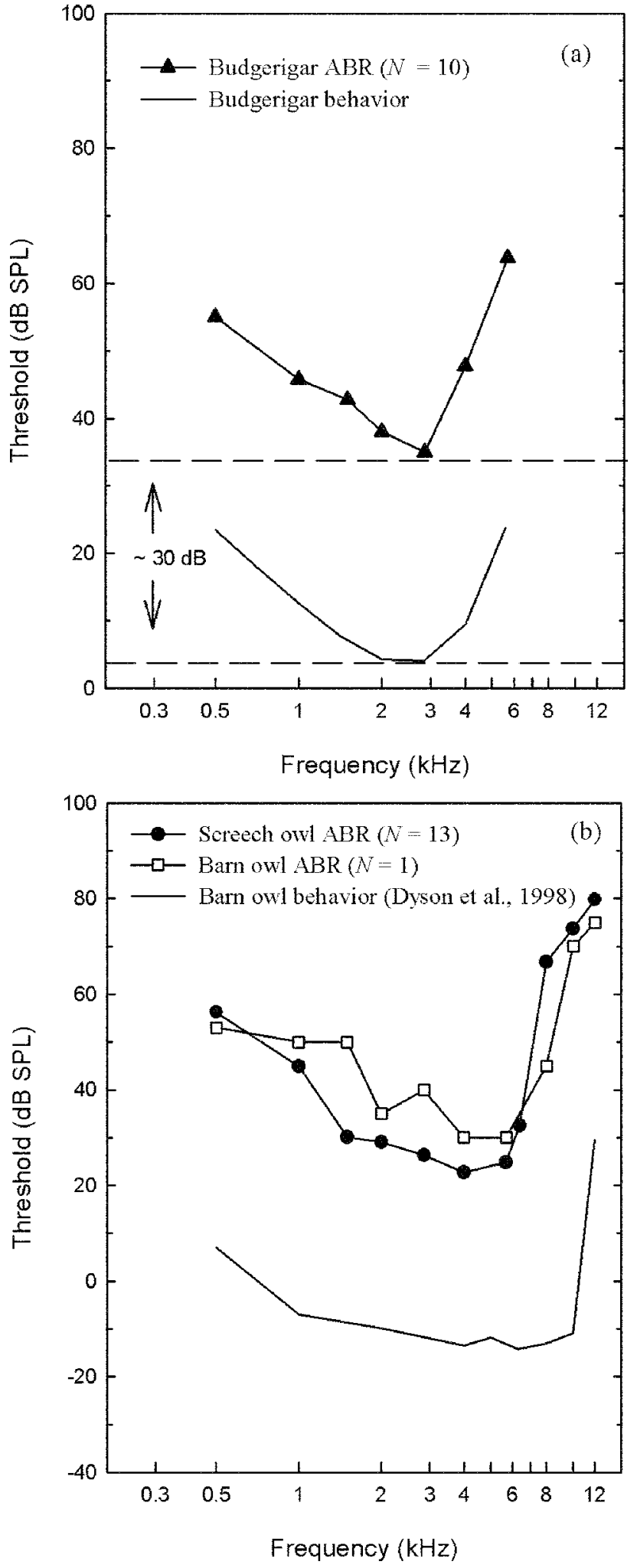

FIG. 5. (a) A comparison of ABR and behavioral audiograms for budgerigars (adapted from Brittan-Powell et al., 2002). Dashed lines represent a typical offset of the ABR audiogram from behavior in birds (see BrittanPowell et al., 2002). (b) A comparison of screech owl (closed circle) and barn owl (open square) ABR audiograms and a barn owl behavioral audiogram (barn owl, solid line, Dyson et al., 1998). The screech owl ABR audiogram is an average of all individuals tested.

It also is possible that differences in our ABR thresholds are not a result of differences in auditory sensitivities, per se, 
but rather an indication of variation in some other feature. For instance, skull size and shape, or neuroanatomical differences, could also contribute to the differences in ABR thresholds measured here. Only a study using behavioral measurements can definitively determine that the rufous color morphs have greater hearing sensitivity. Testing additional birds, collected from other geographical areas, would also provide additional insight. It is possible that at least one gene controlling plumage color in screech owls could be linked to auditory effects. Future studies investigating the relationship between hearing ability and the range of color morphology in this species would help elucidate whether the underlying genetics played a role in the differences we find in ABR sensitivity in the color morphs of this species.

\section{ABR thresholds and vocal ability in birds}

Most birds hear best between 1 and $5 \mathrm{kHz}$ with absolute sensitivity approaching $0-10 \mathrm{~dB}$ SPL at the frequency of best hearing, which is typically around $2-3 \mathrm{kHz}$ (see a review in Dooling et al., 2000). In non-Strigiform birds, peak sensitivity in the audiogram typically coincides with regions of peak energy in the bird's songs and calls (Dooling et al., 2000), reflecting the likely coevolution of hearing and vocalizations. Among nocturnal predatory birds, hearing is thought to have evolved for detecting and localizing prey in the dark (Konishi, 1973; Payne, 1971). Barn owls are known to be highly specialized in this capacity, and they have both good absolute sensitivity and excellent high-frequency hearing compared with other birds (Konishi, 1973). Best auditory sensitivity is in the range of $4-8 \mathrm{kHz}$ for this species, and behavioral auditory thresholds remain below $0 \mathrm{~dB}$ SPL up to 10 kHz (see Fig. 4, Dyson et al., 1998; Konishi, 1973). This degree of specialization and sensitivity may not extend to other species of owls, such as the great horned owl (Bubo virginianus), which appears to exhibit a dramatic decline in hearing ability above $2-3 \mathrm{kHz}$ (Trainer, 1946). Several species of European owls may be somewhat intermediate in their range of best hearing, with most species showing excellent auditory sensitivity to about $6-8 \mathrm{kHz}$, but exhibiting rapid declines in sensitivity above this range (Dyson et al., 1998; Van Dijk, 1973).

Unlike the barn owl, some owls (such as screech owls) are extremely vocal during the breeding season and may use a variety of long-distance acoustic communication signals in the establishment and maintenance of territories. The screech owls (Megascops spp.) have some of the most extensive vocal repertoires among North American owls (Cannings and Angell, 2001; Gehlbach, 1995; Gehlbach and Gehlbach, 2000). The eastern screech owl is fairly typical of many small North American owls, producing long-distance calls with fundamental frequencies (and frequencies of maximum amplitude) between 500-1500 Hz (Cavanagh and Ritchison, 1987; Klatt and Ritchison, 1994). Unlike passerines, the lowest ABR thresholds in the screech owl are at higher frequencies than the peak spectral energy in its vocal signals. This is consistent with the pattern typical of other owls that use hearing for prey detection [see Fig. 4(b)]. Given that the ABR underestimates true hearing sensitivity in other birds by about 30-35 dB over the range of hearing (Brittan-Powell et al., 2002), however, we might expect screech owls to show excellent hearing sensitivity across a range of frequencies that include the frequency regions in which its calls are produced.

\section{CONCLUSIONS}

ABR waveforms in the eastern screech owl are similar in shape and temporal characteristics to those of other birds tested previously (Brittan-Powell and Dooling, 2004; Brittan-Powell et al., 2002; Lucas et al., 2002; Moiseff et al., 1996; Woolley et al., 2001; Woolley and Rubel, 1999; Wright et al., 2004). Likewise, ABR thresholds are similar to those of other birds, but are most comparable to the thresholds of other owls. Like other owls, screech owls show lower thresholds at higher frequencies presumably used in prey detection and localization, despite having an elaborate vocal repertoire concentrated at lower frequencies. Also like other owls, their region of best hearing extends over a broad range of frequencies (Dyson et al., 1998). This broad sensitivity serves for both the detection of prey species and effective vocal communication over long distances. The broad range of sensitivity in screech owls may be adaptive in that it can serve a dual function of facilitating both auditory communication abilities and nocturnal prey detection. Studies of auditory development in this species might also prove interesting in this regard (Hahn, 2004; Kozlowski, 2005).

\section{ACKNOWLEDGMENTS}

The authors would like to thank Amanda Lauer and Michael Osmanski for comments on earlier drafts. We would also like to thank Dr. Catherine Carr for the use of her barn owl (for the ABR audiogram) and Wayne Bauer for animal care and quarantine. This work was supported in part by Grant No. DC04664 from the National Institute of Deafness and Communicative Disorders (NIDCD) of the National Institutes of Health, NIDCD Grant No. DC04762 to BL; National Institutes of Health Grants No. DC00198 and No. DC001372 to RJD, and USGS-Patuxent Wildlife Research Center awards to DCH.

Aleksandrov, L. I., and Dmitrieva, L. P. (1992). "Development of auditory sensitivity of altricial birds: absolute thresholds of the generation of evoked potentials," Neurosci. Behav. Physiol. 22, 132-137.

Borg, E., and Engström, B. (1983). "Hearing thresholds in the rabbit," Acta Oto-Laryngol. 95, 19-26.

Brittan-Powell, E. F., and Dooling, R. J. (2004). "Development of auditory sensitivity in budgerigars (Melopsittacus undulatus)," J. Acoust. Soc. Am. 115, 3092-3102.

Brittan-Powell, E. F., Dooling, R. J., and Gleich, O. (2002). "Auditory brainstem responses (ABR) in adult budgerigars (Melopsittacus undulatus)," J. Acoust. Soc. Am. 112, 999-1008.

Burkard, R., and Voigt, H. F. (1989). "Stimulus dependencies of the gerbil brain-stem auditory-evoked response (BAER): I. Effects of click level, rate, and polarity," J. Acoust. Soc. Am. 85, 2514-2525.

Burkard, R., Jones, S., and Jones, T. (1994). "Conventional and crosscorrelation brain-stem auditory evoked responses in the white leghorn chick: Rate manipulations," J. Acoust. Soc. Am. 95, 2136-2144.

Burkard, R., McGee, J., and Walsh, E. J. (1996a). "Effects of stimulus rate on feline brain-stem auditory evoked response during development. I. Peak latencies," J. Acoust. Soc. Am. 100, 978-990.

Burkard, R., McGee, J., and Walsh, E. J. (1996b). "Effects of stimulus rate on feline brain-stem auditory evoked response during development. II. 
Peak amplitudes," J. Acoust. Soc. Am. 100, 991-1002.

Cannings, R. J., and Angell, T. (2001). "Western Screech-Owl (Otus kennicottii)," in The Birds of North America, No. 597, edited by A. Poole and F. Gill (The Birds of North America, Inc., Philadelphia, PA).

Cavanagh, P. M., and Ritchison, G. (1987). "Variation in the bounce and whinny songs of the Eastern Screech-Owl," Wilson Bull. 99, 620-627.

Corwin, J. T., Bullock, T. H., and Schweitzer, J. (1982). "The auditory brain stem response in five vertebrate classes," Electroencephalogr. Clin. Neurophysiol. 54, 629-641.

Dmitrieva, L. P., and Gottlieb, G. (1992). "Development of brainstem auditory pathway in mallard duck embryos and hatchlings," J. Comp. Physiol. 171, 665-671.

Dmitrieva, L. P., and Gottlieb, G. (1994). "Influence of auditory experience on the development of brain stem auditory-evoked potentials in Mallard duck embryos and hatchlings," Behav. Neural Biol. 61, 19-28.

Donaldson, G. S., and Rubel, E. W. (1990). "Effects of stimulus repetition rate on ABR threshold, amplitude and latency in neonatal and adult Mongolian gerbils," Electroencephalogr. Clin. Neurophysiol. 77, 458-470.

Dooling, R. J., Lohr, B., and Dent, M. L. (2000). "Hearing in birds and reptiles," in Comparative Hearing: Birds and Reptiles, edited by R. J. Dooling, A. N. Popper, and R. R. Fay (Springer-Verlag, New York), pp. 308-359.

Dyson, M. L., Klump, G. M., and Gauger, B. (1998). "Absolute hearing thresholds and critical masking ratios in the European barn owl: a comparison with other owls," J. Comp. Physiol., A 182, 695-702.

Fay, R. R. (1988). "Hearing in Vertebrates: A Psychophysics Databook" (Hill-Fay Associates, Winnetka, IL).

Gehlbach, F. R. (1994). "The Eastern Screech Owl: Life History, Ecology and Behavior in the suburbs and countryside," (University Press, College Station, TX).

Gehlbach, F. R. (1995). "Eastern Screech-Owl (Otus asio)," in The Birds of North America, edited by A. Poole and F. Gill (The Academy of Natural Sciences, Philadelphia, and The American Ornithologists' Union, Washington, DC), pp. 1-24.

Gehlbach, F. R., and Gehlbach, N. Y. (2000). "Whiskered Screech-Owl (Otus trichposis)," in The Birds of North America, No. 507, edited by A. Poole and F. Gill (The Birds of North America, Inc., Philadelphia, PA).

Hahn, D. C. (2004), "Effects of auditory stimulation on embryo development," Report to Patuxent Wildlife Research Center, October 2004.

Hall, J. (1992), "Handbook of Auditory Evoked Responses" (Allyn and Bacon, Boston, MA).

Higgs, D. M., Brittan-Powell, E. F., Soares, D., Souza, M. J., Carr, C. E., Dooling, R. J., and Popper, A. N. (2002a). "Amphibious auditory responses of the American alligator (Alligator mississipiensis)," J. Comp. Physiol., A 188, 217-223.

Higgs, D. M., Souza, M. J., Wilkins, H. R., Presson, J. C., and Popper, A. N. (2002b). "Age- and size-related changes in the inner ear and hearing ability of the adult zebrafish (Danio rerio)," J. Assoc. Res. Otolaryngol. 3, $174-184$.

Jewett, D. (1970). "Volume-conducted potentials in response to auditory stimuli as detected by averaging in the cat," Electroencephalogr. Clin. Neurophysiol. 28, 609-618.

Jewett, D., and Romano, M. (1972). "Neonatal development of the auditory system: Potentials averaged from the scalp of rat and cat," Brain Res. 36, 101-115.

Jewett, D., Romano, M., and Williston, J. (1970). "Human auditory evoked potentials: possible brainstem components detected on the scalp," Science 167, 1517-1518.

Juraschko, K., Meyer-Lindenberg, A., Nolte, I., and Distl, O. (2003). "A regressive model analysis of congenital sensorineural deafness in German Dalmatian dogs," Mamm Genome 14, 547-554.

Katayama, A. (1985). "Postnatal development of auditory function in the chicken revealed by auditory brain-stem responses (ABRs)," Electroencephalogr. Clin. Neurophysiol. 62, 388-398.

Kenyon, T. N., Ladich, F., and Yan, H. Y. (1998). "A comparative study of hearing ability in fishes: the auditory brainstem response approach," $\mathrm{J}$ Comp. Physiol. 182, 307-318.

Klatt, P. H., and Ritchison, G. (1994). "The effect of mate removal on the vocal behavior and movement patterns of male and female Eastern Screech-Owls," Condor 96, 485-493.
Konishi, M. (1973). "How owl tracks its prey,” Am. Sci. 61, 414-424.

Köppl, C., and Nickel, R. (2004), "Prolonged maturation of cochlear function in the barn owl after hatching." (Association for Research in Otolaryngology, Daytona Beach, FL), pp. 55.

Kozlowski, C. P. (2005), "Embryonic vocalizations and parent-offspring communication in the eastern screech owl," MS Thesis, Cornell University.

Lasky, R. E. (1997). "Rate and adaptation effects on the auditory evoked brainstem response in human newborns and adults," Hear. Res. 111, 165176

Lucas, J. R., Freeberg, T. M., Krishnan, A., and Long, G. R. (2002). “A comparative study of avian auditory brainstem responses: correlations with phylogeny and vocal complexity, and seasonal effects," J. Comp. Physiol., A 188, 981-992.

Marti, C. D. (1992). "Barn Owl," in The Birds of North America, No. 1, edited by A. Poole, P. Stettenheim, and F. Gill (The Academy of Natural Sciences, Philadelphia, and The American Ornithologists' Union, Washington, DC).

Moiseff, A., Haresign, T., and Wang, J. (1996). "Sound localization from binaural cues by the barn owl auditory system," in Neuroethological studies of cognitive and perceptual processes, edited by C. F. Moss and S. J. Shettleworth (Westview Press, Colorado), pp. 305-323.

Payne, R. S. (1971). "Acoustic location of prey by barn owls," J. Exp. Biol. 54, 533-573.

Roulin, A., and Wink, M. (2004). "Predator-prey polymorphism: relationships and the evolution of colour a comparative analysis in diurnal raptors," Biol. J. Linn. Soc. 81, 565-578.

Saunders, J. C., Coles, R. B., and Gates, G. R. (1973). "The development of auditory evoked responses in the cochlea and cochlear nuclei of the chick," Brain Res. 63, 59-74.

Stapells, D. R., and Oates, P. (1997). "Estimation of pure-tone audiogram by the auditory brainstem response: A review," Audiol. Neuro-Otol. 2, 257280 .

Strain, G. M., Kearney, M. T., Gignac, I. J., Levesque, D. C., Nelson, H. J., Tedford, B. L., and Remsen, L. G. (1992). "Brainstem auditory-evoked potential assessment of congenital deafness in Dalmatians: associations with phenotypic markers," J. Vet. Intern Med. 6, 175-182.

Theron, E., Hawkins, K., Bermingham, E., Ricklefs, R. E., and Mundy, N. I. (2001). "The molecular basis of an avian plumage polymorphism in the wild: A melanocortin-1-receptor point mutation is perfectly associated with the melanic plumage morph of the bananaquit, Coereba flaveola," Curr. Biol. 11, 550-557.

Trainer, J. E. (1946). "The auditory acuity of certain birds. Doctoral dissertation. Cornell University," in Hearing in vertebrates: a psychophysical databook, edited by R. R. Fay (Hill-Fay Assoc., Winnetka, Illinois).

Umemoto, M., Sakagami, M., Ashida, K., Fukazawa, K., Matsunaga, T., Senda, T., and Fujita, H. (1993). "The ultrastructure of the basilar papilla of the budgerigar's inner ear," Acta Oto-Laryngol. 501, 66-71.

Van Dijk, T. (1973). "A comparative study of hearing in owls of the family strigidae,” Neth. J. Zool. 23, 131-167.

Walsh, E. J., Gorga, M., and McGee, J. (1992). "Comparisons of the development of auditory brainstem response latencies between cats and humans," Hear. Res. 60, 53-63.

Wenstrup, J. J. (1984). "Auditory sensitivity in the fish-catching bat, Noctilio leporinus," J. Comp. Physiol. 155, 91-101.

Wolski, L. F., Anderson, R. C., Bowles, A. E., and Yochem, P. K. (2003). "Measuring hearing in the harbor seal (Phoca vitulina): comparison of behavioral and auditory brainstem response techniques," J. Acoust. Soc. Am. 113, 629-637.

Woolley, S. M., Wissman, A. M., and Rubel, E. W. (2001). "Hair cell regeneration and recovery of auditory thresholds following aminoglycoside ototoxicity in Bengalese finches," Hear. Res. 153, 181-195.

Woolley, S. M. N., and Rubel, E. (1999). "High-frequency auditory feedback is not required for adult song maintenance in Bengalese Finches," J. Neurosci. 19, 358-371.

Wright, T., Brittan-Powell, E. F., Dooling, R. J., and Mundinger, P. (2004). "Sex-linkage of deafness and song frequency spectrum in the Waterslager strain of domestic canary," Proceedings of the Royal Society B (Suppl). Biology Letters, DOI: 10.1098/rsbl.2004.0204. 